\title{
The role of e-marketing as in specific contexts of sports tourism
}

\author{
Daniela Coutinho \\ Escola Superior de Gestão \\ Instituto Politécnico do Cávado e do Ave (IPCA) \\ Barcelos, Portugal \\ e-mail: daniela_sofia_coutinho@hotmail.com
}

Paula Odete Fernandes

UNIAG research member

Instituto Politécnico de Bragança (IPB), Portugal

e-mail: pof@ipb.pt

\author{
Bruno Sousa \\ UNIAG and CiTUR research member \\ Instituto Politécnico do Cávado e Ave (IPCA) \\ Barcelos, Portugal \\ e-mail: bsousa@ipca.pt
}

\begin{abstract}
Athletics is a sport that is going through several difficulties in Portugal, essentially at the financial level, since support and sponsorships are less and less, blocking the construction of financial sustainability, which is reflected in a reduction of medals won in international competitions. Thus, the application of sports and e-marketing to athletics becomes essential, as it will allow us to understand what consumers want, create attachment and paying attention to their preferences, habits and interests. The aim is to promote athletics in Portugal, to provide an increase in the number of sports tourists. The methodology based on the observation of competitions, conducting interviews applied to the study. From the results of this research, it is concluded that athletics disciplines do not meet an adequate e-marketing strategy, with low dissemination in the media. With a focus on some athletics clubs of Portugal and in the Athletics Federation of Portugal, this research aims to contribute to perspectives in the connection between e-marketing and sports tourism, applying specifically to a case study: athletics in Portugal.
\end{abstract}

Keywords - e-marketing, sports tourism, consumer behaviour, athletics.

\section{INTRODUCTION}

Athletics is a group of sports events that involves competitive running, jumping, throwing, and walking [1]. The most common types of athletics competitions are track and field, road running, cross country running, and race walking. Athletics is a sport that is going through several difficulties in Portugal, but that has also offered several achievements to the Portuguese. However, it is at the financial level that the difficulties have been increasing, since support and sponsorships are insufficient, preventing the construction of financial sustainability. These factors have an impact on the number of people interested in the practice of sports, the conditions for regional clubs and those located in more isolated regions and, consequently, the interest by the media to transmit events or news related. In addition, there is a much greater interest and passion for football, in most countries and not just in Portugal, creating a certain dichotomy between athletics and other sports. This is due to the relevance given to football in the media, as a result of the preferences of readers/viewers, so it is a sport that always receives special prominence in the media, even though its function is to publicize the relevant acts concerning various sports, they do not always do so for commercial and financial reasons. The present research contributes to analysing a relatively recent area of study in the marketing and management literature. It was found some studies relative to the subject, although, there aren't so many investigations that involve directly the study of the sports sector. It also contributes to increasing the knowledge for research on brand attachment, which deserves continued attention and exploration because it is far from fully explained. Even though the lack of promotion is a clear obstacle to begin an increase in the public, it is necessary to try to change the consumer's mind and development interest in this group so that its relevance improves, so it becomes more relevant in the media. With the practice of sports becoming more and more a trend, there is an opening to boost the prestige of athletics, given the interest of the population is greater.

\section{E-MARKETING AND CONSUMER BEHAVIOUR}

E-marketing emerged as a response to the market's new demands and the needs of organizations to attract and retain customers and emerged in the areas corresponding to services and industrial marketing. E-marketing is the process of advertising and selling products and services on the internet, for example, on a company website or by email: For cost and efficiency reasons, personal selling is giving the way to telemarketing, call centres, and e-marketing. One of the objectives of marketing is to develop deep and lasting relationships with all the people or organizations that can, directly or indirectly, affect the success of the company's activities [2]. E-marketing brings a transactional approach change, which is reflected in the fact that interdependence and cooperation prevail and stand out for the value's creation [3]. This approach, which considers loyalty to be a key element of relational marketing, is based on the conviction that it costs more to acquire a new customer than to maintain a current one 
and, therefore, the strategic position involves creating a longlasting and well-founded relationship that will contribute to greater competitiveness [4]. The fact that consumers maintain a relationship with brands/organizations brings several benefits: (1) the decision-making process becomes more efficient; (2) the search costs decrease; (3) cognitive consistency in decisions increases; also, relational marketing reduces the complexity and the number of resources needed for the purchase process, as well as it reduces the risk, tension and potential dissonance that grows from the uncertainty and low familiarity that the consumer has regarding the products or services offered [5]. In the online environment, consumers' attitude towards the internet can be fostered by the creativity of websites and as consumers are increasingly demanding and active, the ease of switching websites is high when it doesn't interest them [6]. A website portrays a utilitarian dimension ranging from providing consumer information to communicating new ideas and innovations [7]. It has been nearly a quarter-century since the commercial use of the Internet and the World Wide Web. During this time the business landscape has changed at a frenetic pace. Large multinational corporations such as Google, Facebook, Amazon, Alibaba, eBay and Uber. There is general agreement that digital media have greatly impacted the way a marketer reaches today's consumer. Digital media refer to electronic media that disseminate information in digital formats.

\section{SPORTS MARKETING AND TOURISM}

Sports marketing represents an essential part to maintain communication with the public, and, consequently, stimulates the increase of sports organizations and products [8]. Still, it differs from other forms of marketing and requires new perspectives, which is due to the following aspects: the sports industry, sports products and the consumer himself. Firstly, the sports industry has some peculiarities that are different from other sectors and needs a different approach to marketing. Sports organizations need a certain level of competition, it is impossible to have a monopoly, they do not act with the main objective of generating profits, since these depend heavily on their performance in sport and, finally, the public perception that stands out for their personal involvement with sports organizations and the coverage by social media that extend more than what happens with other sectors or industries [9].

According to [10], sports fans and spectators watch or attend sporting events for different reasons, and identifying their motivations is critical to understanding and satisfying these consumers. Researchers have identified key motivation factors in past research and have developed scales to measure the motives of sport consumers [e.g., 11-14]. The consumer who, in the sports industry, is divided between spectators - individuals who watch a sport and then forget; and fans, who live with more intensity and dedicate part of their time, every day, to their favourite sport or team and demonstrate a high level of loyalty [9]. More than selling products or services that meet consumer needs, sports marketing is built on people's passion and seeks emotional connections [15]. In the context of this study and with the need to understand and meet consumer needs and expectations, each organization must analyse the habits and behaviours of its consumers concerning sport [8]. Nowadays, several sports clubs are implementing these various stages of a marketing strategy to attract more viewers and increase reputation, not only as a team but also as a brand [15].

\section{METHODOLOGY}

In terms of methodology, it is intended to propose a model that investigates the impact of relational marketing in creating a commitment between spectators of athletics and their organizations, including: (1) motivations for practice, overall satisfaction with the practice and organization and commitment/loyalty to the organization/club; (2) organizations difficulties or expectations when attracting spectator individuals; (3) difficulties in reaching a larger number of publics for this sport. The following specific and fundamental objectives are defined to achieve results that can assist in the understanding of this research: (1) define the difficulties of organizations in promoting events to potential spectators; (2) identify the actions taken by sports organizations to capture, attract and retain the public; (3) understand the importance and potential of relational marketing in creating a commitment on the part of athletics spectators and promoting sports organizations to the external public; (4) contribute to the development of theories and e-marketing strategies in the proposed context. the objectives of this study and taking into account the importance of defining a target audience, the following segments are obtained: (1) club/athletics association managers, coaches and members of the IPDJ or FPA, without restrictions on gender and age; (2) athletics practitioners as the target audience of the questionnaires, focusing on the northern region of Portugal; (3) questionnaires that focus on the sportconsuming population in general, without restrictions regarding age, sex or nationality, as a way to complement the remaining information collected. The measurement instruments used to carry out this investigation and according to the defined target audience segments are: semi-structured interviews directed to the first segment; two types of questionnaires, with common questions addressed to segments two - federated athletes from all athletics clubs in Portugal - but with a focus on Mazarefes Athletics Club and segment three - general population.

\section{PRELIMINARY RESULTS AND DISCUSSION}

Athletics in Portugal has demonstrated an enormous capacity to produce excellent results, despite the global competitiveness in this modality, the difficulties that are felt in Portugal with the lack of financial support persist, but that "had a strong implementation in the social organs at the end of the 20th century, a period when middle-distance races produced Olympic champions and medals." - Interviewee A. This is a sport that does not generate attention or retention of the spectators, "although the increase in results in other disciplines was similar, the communication was not able to overcome the lack of presence of these athletes in the events across the country since they can only compete on their specific premises." Interviewee A. Like most of the less prominent sports, the sources of financing are state and municipal subsidies, municipal support, and sponsorship from small and local companies and, finally, there is a percentage of funds from payment of monthly fees from members and athletes. Strictly 
related to the small variation and size of the funding sources, some difficulties are identified. FPA's Communication Director, Interviewee A, lists "the financing of sports activities, without box office receipts; the lack of supporting for maintenance, equipping and revitalizing the existing tracks for the practice of the sport; lack of funding from the overwhelming majority of clubs". This factor is often justified by the lack of public since "it makes sponsors less interested in large-scale support", highlights Interviewee B. In the same way that the financing contributes to the difficulties inherent to the members of athletics associations in Portugal, also the "lack of professional response during practice and little post-practice professional response in the sport, which leads to a huge percentage of abandonment", according to Interviewee A and, also, the "capture of new athletes to replace athletes of the current generations", according to Interviewee B, affect the performance of organizations. Furthermore, "what fails for the overwhelming majority of sports is the nonexistence sports culture. Football, as the main modality, also the one that still offers a short professional window, is not in itself responsible for this lack of culture that comes from a deficient education system that values sport more." - Interviewee A. The interest remains for the "major competitions, European, world and Olympic games. However, it does not seem to be an interest that goes beyond possible medals. " - Interviewee D.

Interviewee B, athlete and certified coach, says that the "lack of coverage of major sporting events by the public media" is one of the reasons for the low number of spectators. In addition, "there is a logistical issue that is difficult to resolve, except for field races, the tracks are hidden, and no one travels to the stadium. It turns out to be a vicious cycle, if there were more money, there would be more competitiveness and, consequently, more public attention", says Interviewee $\mathrm{C}$, sports director at CAM.

In summary, the organizations characterize the respective public as being much diversified, but that expect to make them more informed and to retain them. In this way and using the results obtained in the questionnaires, it is recognized that the sports consumer is not fully aware of the various sports events in athletics, thinking only of the Olympic Games (a large part that corresponds to $47 \%$ ) and of athletics championships (about $26 \%$ ). In turn, the interest of this public in information corresponding to sports competitions under study (international results, event dates, etc.) is also very low, since only $20 \%$ of respondents (34 respondents) claim to seek information on their own. FPA is an entity that has invested more in communication and is motivated to implement actions with people, having outlined new strategies to carry out in the next year. With this, they implemented a marketing department so that it was possible to execute some projects that have planned and implemented "the reformulation of our window on the internet, with a portal that covers all aspects of athletics, from walking and running to high performance; bet on streaming broadcasts from the main competitions (including cable channels); a greater presence of the sport on social networks and other projects to visualize and enhance the results of the best athletes that will be implemented throughout the year; regular presence in major international competitions and support for regional communication" - Interviewee A.

Taking into account the associations studied, the focus is undoubtedly on the use of online channels as they are the most accessible and economical, but to "reach the local communities, where the clubs are located, there must be a social labour in addition to sports", identifies Interviewee D and also a promotion in other communication media. After a quick collection of information, the vast majority of organizations are present on social networks. Besides, it is considered that the results in this modality are not promoted in the best way among the public, but there has been progressed to change what currently happens, which are "sporadically small notes on the last sports pages (...) if good results are achieved at the national level and there are some local press that publishes news about these moments", highlights Interviewee D. It is necessary to expand the communication tools used, "namely the massive dissemination and communication of events, whether on social networks, either in specialized media or public media" adds Interviewee B. In general, the coverage time proposed by the media for athletics must be extended, to have more brands that want to be associated with this sport so that clubs can "cross the threshold of invisibility”, mentions Interviewee C.

It is considered that there is a sensitivity to marketing and its importance in a strategy, as Interviewee D agrees: "it is the tool that drives any club regardless of the modality". However, it is not applied, whether for financial reasons, time or human resources: obstacles that affect the overwhelming majority of sports in Portugal. "[Marketing can be an important catalyst in influencing the interest of the general public] in full synchronization with communication. The implementation of a marketing department at FPA is being fundamental for the execution of some federative projects"- Interviewee A.

\section{CONCLUSIONS}

Sports marketing is a dynamic subject area linking academic research, marketing practitioners and public policy planners. The sport marketing is dynamic because of its polysemic nature as it generates multiple affective means for consumers based on spectator behaviour and receives a high degree of attention due to the involvement of consumers (Vieira \& Sousa, 2020). Based on the strategies applied by the organizations that collaborated in this study, they show sensitivity to marketing, but they still do not apply all available means, either due to lack of financial resources or time availability. There is a concern to communicate coherently and to expand the means of communication used. Currently, its strategy is mainly focused on digital, using social media and online broadcasts. With this preliminary study, it was intended to respond to specific and fundamental objectives to achieve results and understand the proposed case study: (i) define the difficulties of organizations in promoting events to potential spectators; (ii) identify the actions carried out by sports organizations to attract and retain the public; (iii) understand the importance and potential of relational marketing in creating a commitment with athletics spectators and promoting sports organizations to the external 
public; (iv) contribute to the development of theories and/or strategies of relational marketing in the proposed context. From the initial question "How can athletics organizations reach a larger number of spectators in a market in constant change?", emerge the following research question: "Is marketing an important catalyst in influencing the interest of the general public for the modalities of athletics?".

From the perspective of athletics organizations, were conducted semi-structured interviews with people with a responsible role and questionnaires aimed at practitioners of the sport, to obtain a view of the practices adopted, in terms of marketing orientation, relational marketing, target audience (definition, attraction and retention) and communication.

Communication channels used by organizations (clubs, centres, associations and federation): FPA uses physical channels of communication (billboards and posters), digital channels of communication (internet portal, social networks and live broadcasts) and also resources of social communication (press releases). The remaining analysed clubs focus on the use of digital media, particularly social networks. These are the most valued channels to them, simultaneously with word-of-mouth, which has become increasingly important.

Investment in communication plans and marketing strategies: there is no investment in this area that can be clearly measured. Except for the FPA, which has new plans for the current year, to improve the presence of the sport.

Methods used to attract and retain the public: organizations characterize their audience as being very diverse and do not use methods to analyse their target audience. Thus, not many marketing techniques are used to attract the intended audience, resulting in a low number, not only of practitioners but essentially of spectators.

The importance of relational marketing: there is evidence of relational marketing practice: trying to get close to people, create a relationship with them and make them loyal to the sport. Considering all the important relationships, there is a growing interest in communicating with quality to the indicated audiences and with the appropriate methods.

It is important to promote actions with the community, to fill the gaps in the sports culture. To complement this investigation, some actions are suggested based on quantitative and qualitative research and, also, on the observation of regional competitions. It is suggested the promotion of actions in the schools so that children and younger people can experience the modalities and have a choice when they intend to practice a sport and also it is important to keep sending out continuous press releases, although it is difficult to find prominence for athletics. It is also important to implement digital marketing actions as these are low-cost strategies and available to all clubs, while investing in physical channels, such as billboards and mupis, since they are still in use and work as a method of creating awareness through the communities. it is essential to disseminate the posters of the competitions since it is difficult to find this type of information unless you have some knowledge of the primary online sites where you should search. Last but not least, and to make the various modalities of athletics known to a younger generation and to relate, from an early age, with the various sports in
Portugal, it is suggested to organize study tours to the HighPerformance Centre.

It is expected that the discussion about sports marketing and e-marketing has explained how the marketing strategies adopted by sports organizations are positively reflected in the public, in terms of attraction, retention and loyalty. This investigation aggregates information about the current situation of the sport in Portugal: the communicative techniques used, and the marketing strategies implemented by the organizations associated with athletics. Generically, it highlights the importance of adapting and adopting new measures for attracting and retaining stakeholders (athletes and spectators). In terms of sport, it offers new perspectives on athletics and contributes to an expansion of knowledge about the communication of some clubs, strategic changes in the FPA regarding their communication and marketing tools. Although there is a significant increase in interest and value given to marketing, there are few efforts to implement strategies.

In this research, it is possible to identify some limitations that were felt throughout the respective elaboration. The first limitation relates to quantitative research and the fact that it was used as a complement to qualitative research, which can be improved by conducting additional in-depth interviews and, subsequently, an analysis using appropriate software. The second one is related to the number of samples acquired from the questionnaires, which was reduced when compared to the total population under study, which corresponds to all sports consumers in Portugal, practitioners and athletics sports associations. Thirdly, appears a limitation related only to athletics as the study area. In this way, the study may be deepened with other sports areas, for possible comparison between the various sports practised in Portugal. Also, there are limited available bibliography related to athletics and its status in Portugal or Europe. It is also noteworthy the difficulty in scheduling the interviews, causing a delay in the previously defined schedule. In future studies, it is important to continue with quantitative research and to test causal relationships between the selected variables. It is also necessary to propose study hypotheses and test them empirically using the SPSS software. It is possible to focus on the need to analyse the theme and correlate with other European countries and observe and implement its best practices, as a benchmarking technique. Finally, it is proposed to extend the study to other sports organizations to compare and also to understand their status in Portugal.

Therefore, sports tourism is understood as active participation, as a practitioner, or passive, as a spectator, in recreational or competitive sports, with sport being the fundamental motivation for travelling and the destination is defined by the qualities offered for the practice of that same sport. On the other hand, some authors judge sports tourism to be subdivided into more subtypes, such as [16] who states that this type of tourism is described in three forms: "active sport tourism where participants travel to be part of the sport", "sports tourism event where participants travel to be observers" and "tourism nostalgia" sport where participants visit attractions related to sport such as famous stadiums". Consequently, and as 
an example, the Champions League to be held in Lisbon, in the future to attract international tourists, thus increasing the notoriety of the destination brand Portugal, specifically Lisbon, football being an attraction for both national and international tourists due to its affection, related to the phenomenon in question and your own club. In future works, it is intended to develop the study using qualitative methodology, showing that feelings of affection and love for brands will influence the purchasing decision of consumers-supporters. It will be our purpose, in future investigations, to conduct semi-structured interviews with professionals and managers related to sports tourism in Portugal as well as consumers with fans-tourists, through a focus group. With the insights from this study, it is expected that future work can contribute to the development of empirical studies to address the developed propositions in different countries. In particular, it is expected that future research explores the relationship between attachment, satisfaction and loyalty of football supporters in qualitative and quantitative studies. Studies could further develop a questionnaire to be applied to football fans to capture a crosssectional view of the relationships among the constructs gauging their impact. In future research, we intend to show shows how these valid questions can be answered by introducing causal modelling and discussing one approach to it, structural equation modelling (SEM). From an interdisciplinary perspective, the present study presents contributions to niche tourism (i.e. sports tourism) and consumer behaviour in brand contexts (i.e. brand love and brand engagement).

\section{ACKNOWLEDGEMENT}

UNIAG, R\&D unit funded by the FCT - Portuguese Foundation for the Development of Science and Technology, Ministry of Science, Technology and Higher Education. Project no. UIDB/04752/2020.

\section{REFERENCES}

[1] Athletics"Oxford English Dictionary (3 $3^{\text {rd }}$ ed.). Oxford University Press. December 2013

[2] P. Kotler. Marketing Management. (11st ed.). New Jersey: Pearson education, Upper Saddle River, 2003.

[3] V. Vilas-Boas, B. Sousa, and P.O. Fernandes. Trust and perceived risk in consumer behaviour: A preliminary study in electronic commerce. Proceedings of the 33rd International Business Information Management Association Conference, IBIMA 2019: Education Excellence and
Innovation Management through Vision 2020, 2019, pp. 4883-4894, ISBN: 978-0-9998551-2-6

[4] G.M. Alves, B. Sousa, B. M., and A. Machado. The Role of Digital Marketing and Online Relationship Quality in Social Tourism: A Tourism for All Case Study. In J. Santos, \& Ó. Silva (Eds.), Digital Marketing Strategies for Tourism, Hospitality, and Airline Industries, 2020, pp. 4970. Hershey, PA: IGI Global. doi:10.4018/978-1-5225-9783-4.ch003

[5] C.C. Bee, and L.R. Kahle. Relationship Marketing in Sports: A Functional Approach. Sport Marketing Quarterly. Vol. 15, n. ${ }^{\circ}$ 2, 2006, pp. 102-110.

[6] L. Ferreira, L., and B. Sousa. Understanding the Role of Social Networks in Consumer Behavior in Tourism: A Business Approach. In C. Ramos, C. Almeida, \& P. Fernandes (Eds.), Handbook of Research on Social Media Applications for the Tourism and Hospitality Sector, 2020, pp. 367-384. IGI Global. doi:10.4018/978-1-7998-1947-9.ch021.

[7] B. Moon. Consumer adoption of the internet as an information search and product purchase channel: Some research hypotheses. International Journal of Internet Marketing and Advertising, 1(1), 2004, p. 104. doi:10.1504/IJIMA.2004.003692

[8] C.B. Vieira, and B. Sousa. The brand attachment and consumer behaviour in sports marketing contexts: the case of football fans in Portugal, Int. $J$. Sport Management and Marketing, Vol. 20, Nos. 1/2, 2020, pp.29-46. https://doi.org/10.1504/IJSMM.2020.10032047

[9] A. Bühler, G. Nufer, and C. Renhank. The nature of sports marketing. Reutlingen Working Papers on Marketing \& Management. Reutlingen University, 2006.

[10] S. Kim, T.C. Greenwell, D.P. Andrew, J. Lee, and D.F. Mahony. An analysis of spectator motives in an individual combat sport: A study of mixed martial arts fans. Sport Marketing Quarterly, 17(2), 2008, p. 109.

[11] D. Funk, D. Mahony, and L. Ridinger. Characterizing consumer motivation as individual difference factors: augmenting the Sport Interest Inventory (SII) to explain level of spectator support. Sport Marketing Quarterly, 11(1), 2002, pp. 33-44.

[12] L.R. Kahle, K.M. Kambara, and G.M. Ross. A functional model of fan attendance motivations for college football. Sports Marketing Quarterly, 5(4), 1996, pp. 51-60.

[13] A. Tapp, and J. Clowes. From "carefree casuals" to "professional wanderers" Segmentation possibilities for football supporters. European Journal of Marketing, 36(11/12), 2002, pp. 1248-1269.

[14] N.D. Theodorakis, N. Tsigilis, and K. Alexandris. The mediating role of place attachment on the relationship between service quality and loyalty in the context of skiing. International Journal of Sport Management and Marketing, 6(3), 2009, pp. 277-291.

[15] D. Panagiota, and N. Vasiliki. The power of Marketing in the Industry of Sports. Master Thesis. School of Economics, Business Administration \& Legal Studies, International Hellenic University, Thessaloniki, Grécia, 2018.

[16] A.J. Peixoto, and B. Sousa. Sports and Emotions in Tourism Marketing Management: A Preliminary Study in Football in Portugal. In: de Carvalho J.V., Rocha Á., Liberato P., Peña A. (eds) Advances in Tourism, Technology and Systems. ICOTTS 2020. Smart Innovation, Systems and Technologies, vol 208, 2021, Springer, Singapore. https://doi.org/10.1007/978-981-33-4256-9_33 